\title{
CORRIGENDUM
}

\section{The role of the 'lifestyle' label and negative bias in the allocation of health resources for erectile dysfunction drugs: an ethics-based appraisal}

H Manson

International Journal of Impotence Research (2006) 18, 221. doi:10.1038/sj.ijir.3901419

Correction to: International Journal of Impotence Research (2006) 18, 98-103. doi:10.1038/sj.ijir.3901409

Following the publication of this article, the author identified the following errors:

1. In the last paragraph on page 102, the text should end at 'There is a lot more depth to consider'. The rest of the paragraph should be considered a separate footnote to the paper.

2. In the last paragraph, also on page 102 in the footnote text, the correct spelling is 'Viagra Drug Development Team'. 